\title{
»Die Polizei der Gene« - Genetische Diskriminierung und die Fallstricke der Kritik
}

\author{
Von Thomas Lemke
}

»Warum sollte man nicht von einer Jagd auf heterodoxe Gene, von einer genetischen Inquisition träumen? [...] Für manche Biologen von sehr unterschiedlicher, wenn man einmal so sagen darf: philosophischer Überzeugung sind solche Träume keineswegs nur Träume. Träumt man sie indessen, so betritt man eine andere Welt, die jener besten aller Welten Aldous Huxleys durchaus benachbart ist und aus der die kranken Individuen mitsamt ihren eigenartigen Krankheiten und Ärzten entfernt sind. Man stellt sich hier das Leben einer natürlichen Bevölkerung vor gleich einer Losurne: Bestellte Beamte werden von der Wissenschaft vom Leben eingesetzt, die Richtigkeit der in der Urne enthaltenen Nummern zu prüfen, bevor die Spieler sie herausfischen und ihre Karten damit zieren dürfen. Begonnen hatte dieser Traum einmal mit dem hochherzigen Wunsch, unschuldigen und ohnmächtigen Lebewesen die schreckliche Belastung zu ersparen, stellvertretend an den Irrtümern des Lebens zu tragen. An seinem Ende allerdings steht die Polizei der Gene, die beschirmt wird von der Wissenschaft der Genetiker.« (Canguilhem 1977:196)

In den vergangenen fünfzehn Jahren hat eine Reihe von empirischen Studien in verschiedenen Ländern den Nachweis erbracht, dass das zunehmende genetische Wissen zu neuen Formen von Ausgrenzung, Benachteiligung und Stigmatisierung führt (Billings et al. 1992; Geller et al. 1996; Low et al. 1998; Otlowski et al. 2002). ${ }^{1}$ Das Spektrum dieser »genetischen Diskriminierung « reicht von Benachteilungen im Arbeitsleben über Probleme mit Versicherungsverträgen bis hin zu Schwierigkeiten mit Adoptionsagenturen. So wurde etwa in einigen Fällen mit dem Hinweis auf eine eventuelle spätere Krankheit die Qualifikation für einen Arbeitsplatz abgesprochen und die Einstellung verweigert. Ebenso kündigten Kranken- und Lebensversicherungen Verträge oder verweigerten deren Abschluss, wenn bei ihren (potenziellen) Kunden der Verdacht auf genetische Erkrankungsrisiken bestand. In anderen Fällen wurde Ehepaaren die Adoption von Kindern untersagt, wenn bei einem der Elternteile eine Disposition für eine genetische Krankheit vorlag. Berichte über Erfahrungen genetischer Diskriminierung kamen jedoch auch aus dem Gesundheitswesen, dem Bildungssektor und dem Militär. $^{2}$

Die empirischen Studien zum Problem genetischer Diskriminierung blieben nicht ohne Resonanz. In der wissenschaftlichen und gesellschaftspolitischen Diskussion wurde die Gefahr einer »genetischen Unterschicht « (Nelkin 1995:209) oder »neuer Parias« (Kitcher 1998:169) beschworen: Menschen, die aufgrund ihrer genetischen Eigenschaften benachteiligt, pathologisiert und stigmatisiert werden. Die Ängste vor einer »neuen Form des sozialen Vorurteils« (Rifkin 2000) haben zu vielfältigen Regulierungsbemühungen geführt. Seit Beginn der

1) Dieser Artikel beruht auf Arbeiten im Rahmen eines Forschungsprojekts, das von der DFG unter dem Titel »Genetische Diagnostik in der Risikogesellschaft« gefördert und am Institut für Sozialforschung in Frankfurt am Main durchgeführt wurde. Viele Ideen und Anregungen zu diesem Text gehen auf Diskussionen mit Mitgliedern der Genetic Screening Study Group in Boston und Vertretern des Council for Responsible Genetics in Cambridge/ Mass. zurück. Bedanken möchte ich mich vor allem bei Joseph Alper, Jon Beckwith, Peter Conrad, Lisa N. Geller und Sujatha Byravan sowie bei Diane Paul und Sarah Jensen. Für Kritik und Kommentare an einer ersten Fassung des Manuskripts danke ich Susanne Krasmann, Sigrid Graumann und Ulrich Bröckling.

2) Für einen Überblick über bislang vorliegende Studien zu Erfahrungen genetischer Diskriminierung s. Lemke/ Lohkamp 2005. 
1990er Jahre erfolgte eine Reihe von gesetzgeberischen Initiativen und Stellungnahmen interund supranationaler Organisationen und Kommissionen, um Menschen vor genetischer Diskriminierung zu schützen. Ein explizites Verbot von Diskriminierung aufgrund genetischer Merkmale enthalten etwa die Biomedizin-Konvention des Europarates (Art. 11), die Deklaration über das menschliche Genom der UNESCO (Art. 6), und die Charta der Grundrechte der EU (Art. 21). Ebenso erließen viele Staaten Regelungen, die sicherstellen sollen, dass niemand aufgrund seiner genetischen Konstitution benachteiligt wird. So ist in einigen Staaten, darunter Österreich und Belgien, eine genetische Diskriminierung von Menschen grundsätzlich verboten. In den USA wurden schon frühzeitig spezielle Gesetze in den Einzelstaaten wie auf bundesstaatlicher Ebene verabschiedet. Weitere Gesetzesinitiativen zum Schutz vor genetischer Diskriminierung werden derzeit beraten - unter anderem in Deutschland.

Mittlerweile wird jedoch immer deutlicher, dass das Konzept der genetischen Diskriminierung, wie es in wissenschaftlichen Studien und Gesetzestexten verwendet wird, eine Reihe von theoretischen, normativen und praktischen Schwierigkeiten aufweist. In diesem Beitrag sollen vier Problemkomplexe eingehender behandelt werden, die wichtige Lücken und Schwächen der Auseinandersetzung mit genetischer Diskriminierung aufzeigen: Diskrepanzen in der forschungspraktischen Verwendung des Diskriminierungsbegriffs (1); empirische Defizite, die zentrale Arenen genetischer Diskriminierung nicht erfassen (2); konzeptionelle Probleme, eine wissenschaftliche Sonderstellung genetischer Informationen zu begründen (3); schließlich normative Ambivalenzen, da die Vorstellung einer besonderen Schutzwürdigkeit genetischer Daten im Vergleich zu nichtgenetischen Informationen zu einer ungerechtfertigten Ungleichbehandlung von Betroffenen führt (4). Das zentrale Argument des Beitrags lautet, dass die theoretische und politisch-rechtliche Kritik an Praktiken genetischer Diskriminierung häufig selbst auf der impliziten Vorstellung beruht, dass Gene menschliche Existenz in fundamentaler Weise prägen und sie den Kern der Persönlichkeit ausmachen. Meine Vermutung ist, dass die essentialistische Konzeption eines genetischen Programms, das für die individuelle Entwicklung wie für die persönliche Identität eines Menschen verantwortlich sein soll, die verborgene Grundlage der Kritik bildet. Im letzten Teil sollen einige vorläufige Schlussfolgerungen aus dieser Beobachtung für die weitere wissenschaftliche und politische Diskussion genetischer Diskriminierung gezogen werden (5).

\section{Begriffliche Diskrepanzen: Umfang und Inhalt genetischer Diskriminierung}

In der wissenschaftlichen Literatur, aber auch in den Medien und einschlägigen Gesetzestexten bezeichnet genetische Diskriminierung eine Ungleichbehandlung von Menschen aufgrund vermuteter oder tatsächlicher genetischer Besonderheiten. Dabei wird genetische Diskriminierung meist strikt von Diskriminierung aufgrund von Behinderung und Krankheit unterschieden (Billings et al. 1992:477; Natowicz et al. 1992:466). Alle relevanten empirischen Untersuchungen griffen diese Definition genetischer Diskriminierung auf, ihre forschungspraktische Anwendung fiel jedoch sehr unterschiedlich aus - was die Vergleichbarkeit der Untersuchungsergebnisse erschwert.

Lapham et al. (1996) verwenden für ihre Arbeit einen sehr weiten Diskriminierungsbegriff, der nicht nur präsymptomatische Fälle einschließt, sondern auch solche, bei denen die Betroffenen bereits erkrankt sind. Daher werden phänotypische und genotypische Merkmale gleichermaßen als Grundlage der Bestimmung einer genetischen Diskriminierung herangezogen. ${ }^{3}$ Die meisten anderen Untersuchungen wollen von genetischer Diskriminierung ge-

3) Vgl. auch die umfassende Definition, die Therese Neuer-Miebach (2001:54) vorschlägt: »Als genetische Diskriminierung bezeichne ich eine Benachteiligung auf der Basis einer genetischen Veranlagung, die zu Behinderung und/oder Krankheit führt, oder einer genetisch bedingten Krankheit, eines Behinderungs- und Krankheitsrisikos.« 
gen Betroffene hingegen nur dann sprechen, wenn die Krankheitssymptome sehr milde ausfallen oder sie keine Behinderung bzw. Leistungseinschränkung darstellen (s. Billings et al. 1992; Geller et al. 1996). Extrem eng gefasst ist hingegen der Diskriminierungsbegriff, den Mark A. Hall und Stephen S. Rich ihrer Studie zugrunde legen. Sie berücksichtigten für ihre Untersuchung nur Fälle, in denen die Betroffenen vollständig präsymptomatisch waren, sich also die Krankheit in keiner Weise manifestiert hat. Die unterschiedlichen Diskriminierungsbegriffe führen zu gegensätzlichen Ergebnissen: Während Hall und Rich Mühe hatten, überhaupt einen einzigen Fall von genetischer Diskriminierung zu dokumentieren, hat der Studie von Lapham et al. zufolge fast die Hälfte der Befragten Erfahrungen mit genetischer Diskriminierung gemacht (Hall/ Rich 2000:294; Hellman 2003:86). ${ }^{4}$

Aber nicht nur der Umfang, auch der Inhalt des Diskriminierungsbegriffs ist innerhalb der wissenschaftlichen Diskussion umstritten. In einschlägigen Untersuchungen wird unter genetischer Diskriminierung regelmäßig eine »ungerechtfertigte Ungleichbehandlung von Menschen aufgrund ihrer genetischen Ausstattung « verstanden (Deutscher Bundestag 2002:288). Die Literatur zeichnet sich meist durch eine kritische Perspektive aus: Es wird implizit davon ausgegangen, dass eine Ungleichbehandlung aufgrund faktischer oder vermuteter genetischer Unterschiede rechtlich unzulässig und/oder moralisch verwerflich sei. Neben dieser Mehrheitsauffassung gibt es jedoch auch andere Stimmen, die in genetischer Diskriminierung eine sachlich gerechtfertigte Risikodifferenzierung sehen. ${ }^{5}$ Eine Extremposition markiert in dieser Hinsicht die libertäre Argumentation von Colin S. Diver und Jane Maslow Cohen (2001). Ihnen zufolge ist eine Ungleichbehandlung von Menschen auf der Grundlage genetischer Faktoren nicht nur moralisch unproblematisch und rechtlich zulässig, sondern als ökonomisches Mittel der Ressourcenallokation und Risikokalkulation gesellschaftlich geboten. In dieser Perspektive bedrohen staatliche Verbote genetischer Diskriminierung eine effiziente Marktregulation, die ein $»$ Regime genetischer Transparenz« erfordere (S. 1482). ${ }^{6}$

Die begrifflichen Diskrepanzen sind natürlich nicht nur von forschungsstrategischem oder theoretischem Interesse, sondern von großer rechtspraktischer und gesellschaftspolitischer Bedeutung: Ist genetische Diskriminierung ein legitimes Mittel der Risikodifferenzierung, um wirtschaftliches Wachstum und Wohlstand zu produzieren oder ein gesellschaftliches Übel, das entsprechende staatliche Schutzmaßnahmen für Betroffene erfordert? Und wenn Letzteres der Fall ist, welche Individuen und Gruppen mit welchen Krankheiten bzw. Krankheitsrisiken sollen in welcher Weise vor Diskriminierung geschützt werden? Wie weit oder wie eng soll der Kreis derjenigen gezogen werden, die von einem rechtlichen Schutz profitieren?

\section{Empirische Defizite: »Alltagseugenik« und indirekte Diskriminierung}

Die bislang vorliegenden Studien zum Problem genetischer Diskriminierung weisen einen klaren Schwerpunkt auf. Im Zentrum steht das Problem der Benachteiligung von Individuen

4) Auch William Nowlan und Philip R. Reilly vertreten eine enge Interpretation genetischer Diskriminierung und halten die Bedeutung des Problems für weit überschätzt (Nowlan 2003; Reilly 1999).

5) Für eine kurze Gegenüberstellung der beiden Pole der Diskussion s. Somek 2003:37-39.

6) Bei Beschäftigungsverhältnissen erlaube etwa der Einsatz genetischer Untersuchungsverfahren, unproduktive oder krankheitsanfällige Arbeitnehmer gar nicht erst einzustellen und damit Kosten zu sparen: »Hiring or promoting an underqualified or underproductive worker is inevitably costly to the employer. [...] Monitoring and corrective action require investment in supervision, and often require changes in production design or scheduling. In the meantime, the underperforming worker inflicts on the organization both demoralization costs and the opportunity costs of foregone output. For these reasons, it is almost always in the employer's interest to establish better ex ante screening mechanisms so as to select workers who will require less supervision and corrective action « (Diver/ Cohen 2001:1461). 
und deren Familienangehörige durch institutionelle Akteure. Diese analytische Konzentration kann jedoch wichtige Praxisfelder genetischer Diskriminierung nicht erfassen. Im Folgenden sollen zwei empirische Defizite genauer behandelt werden: die Fokussierung auf institutionelle Akteure und die Vernachlässigung indirekter Diskriminierungsformen. ${ }^{7}$

\subsection{Konzentration auf institutionelle Akteure und asymmetrische Entscheidungsprozesse}

Eine Schwäche bisheriger Analysen genetischer Diskriminierung ist deren Fokussierung auf institutionelle Akteure einerseits und Individuen bzw. Familienangehörige andererseits. Diese Gegenüberstellung bleibt noch zu sehr einem juridischen Täter-Opfer-Schema verhaftet. So richtig und wichtig es ist, diskriminierende Praktiken von Versicherungen, Arbeitgebern, Adoptionsstellen und anderen Organisationen aufzudecken, eine entscheidende Arena genetischer Diskriminierung wird auf diese Weise nicht erfasst: die Missachtung und Stigmatisierung im Familien- und Freundeskreis, durch Bekannte und Mitmenschen. Diese »Alltagsdiskriminierung « wird in den vorliegenden Arbeiten systematisch ignoriert, so dass ein möglicherweise wichtiges Feld genetischer Diskriminierung ausgeklammert bleibt.

Diese analytische Lücke wird ergänzt durch ein weiteres Problem: Die bisherige Literatur $\mathrm{zu}$ genetischer Diskriminierung konzentriert sich auf »negative« Prozessmuster: auf zwangsförmige Verfahren und asymmetrische Entscheidungsprozesse. Als Leitvorstellung fungieren Organisationen, die Verträge verweigern oder Qualifikationen absprechen. Auf diese Weise bleibt ausgeblendet, inwieweit auch formal freiwillige Handlungsoptionen und symmetrische Entscheidungssituationen diskriminierende Effekte haben können. Viele Beobachter konstatieren einen Übergang von einer Zwangseugenik zu eher indirekten Formen der Lenkung und Führung von Individuen, die in der wissenschaftlichen Diskussion etwa als »freiwillige« (Weß 1992) »individualistische« (Waldschmidt 1996:275) oder »liberale Eugenik « (Habermas 2001) bezeichnet wird. An die Stelle staatlich verordneter eugenischer Programme, die v.a. auf repressive Mittel zurückgriffen (von Zwangssterilisationen bis zum Völkermord), tritt eine Art »Alltagseugenik« (Degener/ Köbsell 1992:67-92), die im Namen von Selbstbestimmung, Verantwortung und Wahlfreiheit auftritt und auf die produktive Optimierung der Lebensqualität zielt. Nicht Ver- oder Gebote, sondern genetische Beratung und wissenschaftliche Aufklärung über Chancen und Risiken bestimmen den aktuellen humangenetischen Diskurs. Damit stellt sich die Frage, ob sich das Phänomen genetischer Diskriminierung auf konkrete Einzelfälle und seltene Ausnahmeerscheinungen beschränkt, oder es auf »normalen« Risikokalkülen, »rationalen« Gesundheitskonzepten sowie der Idee einer »selbstregulativen Verhaltenssteuerung « beruht (Weingart 1992:45-49).

\subsection{Konkrete Fälle und indirekte Mechanismen}

Die angeführten Probleme zeigen die Grenzen eines personenzentrierten und fallorientierten Diskriminierungsbegriffs. Neben einer direkten Diskriminierung von Menschen, die unmittelbar mit Benachteiligung oder Stigmatisierung konfrontiert sind, müssen auch Formen einer »indirekten « Diskriminierung Berücksichtigung finden. Darunter sollen alle Faktoren verstanden werden, die mittelbar auf Betroffene einwirken und deren Entscheidungsspielräume und Handlungsoptionen beschränken. Während direkte genetische Diskriminierung einzelfallbezogen bleibt und die Art und Weise meint, wie bestimmte Menschen mit genetischen Eigenheiten individuell behandelt werden, bezieht sich indirekte Diskriminierung auf

7) Die folgenden Ausführungen stützen sich maßgeblich auf die Ergebnisse einer empirischen Studie zu Erfahrungen von Betroffenen der Huntington-Krankheit mit genetischer Diskriminierung, die der Verfasser durchgeführt hat (Lemke 2005). 
jene sozialen Unwerturteile, Vorurteilsstrukturen und Formen von Missachtung, die an alle Gesellschaftsmitglieder adressiert sind. ${ }^{8}$

Eine umfassende Analyse genetischer Diskriminierung muss auch jene Handlungsstrategien in den Blick nehmen, mit denen Betroffene eine negative Kategorisierung durch das soziale Umfeld antizipieren und ihr Verhalten darauf einstellen. Das wirksamste Mittel, um genetischer Diskriminierung vorzubeugen, besteht darin, Mitmenschen und institutionellen Akteuren wie Versicherungen oder Arbeitgeber genetische Risiken nicht zur Kenntnis zu bringen. Diese »Informationskontrolle« erstreckt sich von der Partnerwahl über Nachbarschaftsbeziehungen bis ins Arbeitsleben. Die Ausklammerung des eigenen Erkrankungsrisikos und der Ängste, die damit einhergehen, wird von den Betroffenen selbst als eine Form des Zwangs erfahren, als eine Einschränkung von Kommunikationsformen und als Notwendigkeit, anderen wichtige Informationen über sich selbst und die eigene Zukunft vorzuenthalten (s. Konrad 2003).

Darüber hinaus hat das Unwerturteil, das in Praktiken genetischer Diskriminierung zum Ausdruck kommt, auch Auswirkungen auf Reproduktionsentscheidungen, die weit über den Kreis derer hinausgehen, die unmittelbar von genetischen Krankheitsrisiken betroffen sind. Konzentrierten sich die bisherigen Untersuchungen zum Problem genetischer Diskriminierung auf postnatale Gentests und die Benachteiligung bereits geborener Menschen, so ist zu fragen, ob die Analyse nicht auch den Bereich der Pränataldiagnostik (selektive Abtreibung aufgrund genetischer Indikation) und der Präimplantationsdiagnostik (gezielte Auswahl genetisch »erwünschter« Embryonen) erfassen sollte (s. Neuer-Miebach 2001:56-59; Volz 2003).

Für eine systematische Analyse genetischer Diskriminierung ist es jedoch nicht ausreichend, eine interne Differenzierung genetischer Diskriminierungspraktiken vorzunehmen. Darüber hinaus müssen auch »strukturelle Kopplungen ${ }^{9}$ zwischen verschiedenen Diskriminierungsformen berücksichtigt werden. Auf diese Weise kann untersucht werden, wie sich Formen genetischer Diskriminierung mit sexistischen und rassistischen Praktiken verbinden und sie einander wechselseitig verstärken (Wolf 1995; Andrews 2001:77-97).

Was das Verhältnis von genetischer Diskriminierung und Rassismus angeht, ist festzustellen, dass einige genetische Krankheiten gehäuft in bestimmten Ethnien und Bevölkerungsgruppen zu finden sind. So tritt bei Menschen afrikanischer Herkunft das Sichelzellenallel relativ häufig auf, das Tay-Sachs-Syndrom ist unter den aschkenasischen Juden besonders verbreitet, und unter der Bevölkerung des Mittelmeerraums finden sich die meisten Träger des Gens für Beta-Thalassämie. Da verschiedene ethnische Gruppen in unterschiedlicher Weise anfällig für bestimmte genetische Krankheiten sind, besteht die Gefahr, dass Angehörige von Minderheiten mit solchen Genen in Zusammenhang gebracht und pathologisiert werden, selbst wenn sie keine Mutationsträger sind. So wird die Sichelzellenanämie in den

8) Vgl. dazu die Unterscheidung der Enquetekommission »Recht und Ethik der modernen Medizin«: »Direkte Diskriminierung bedeutet eine moralisch nicht gerechtfertigte Ungleichbehandlung oder Ausgrenzung von Menschen durch andere Menschen bzw. Institutionen. Darunter wäre etwa die Diskriminierung von Arbeitnehmerinnen und Arbeitnehmern oder von Versicherten oder Menschen mit Behinderung auf der Grundlage von Gentests zu verstehen. Unter indirekter Diskriminierung sind soziale Werte und Normen zu verstehen, die eine Geringschätzung bestimmter Menschen ausdrücken. Darunter würde die Etablierung gesellschaftlicher Normen wie beispielsweise ,Lebenswertzuschreibungen< aufgrund chronischer Krankheit oder Behinderung fallen« (Deutscher Bundestag 2002:57). Deborah Hellmans »expressivist argument « zielt auf eine ähnliche Unterscheidung (2003:108).

9) Ich verwende den Begriff der »strukturellen Kopplung « außerhalb des systemtheoretischen und kognitionswissenschaftlichen Kontextes (s. etwa Luhmann 1997:92ff., 100ff.). Mir kommt es hier v.a. auf den Zusammenhang von operativer Eigenständigkeit und wechselseitiger Abhängigkeit unterschiedlicher Diskriminierungsformen an, die der Begriff gut erfasst. 
USA als Erkrankung der Afro-Amerikaner betrachtet, obwohl sie bei Bevölkerungsgruppen, die aus dem Mittelmeerraum stammen, ähnlich häufig anzutreffen ist (Duster 1991:24-28, 45-51). Ebenso besteht die Gefahr, dass es zu Ungleichheiten in der Ressourcenverteilung und in der öffentlichen Aufmerksamkeit für diese Krankheiten kommt. So erhält in den USA beispielsweise die Forschung zu Cystischer Fibrose, die vor allem Menschen mit weißer Hautfarbe betrifft, deutlich mehr Fördergelder als jene zur Sichelzellenanämie, auch wenn letztere in der Gesamtbevölkerung wesentlich verbreiteter ist (European Commission 2004:50). ${ }^{10}$

Ein anschauliches Beispiel für die Verbindung von genetischer Diskriminierung und Sexismus ist etwa die Praxis der gender verification bei sportlichen Wettbewerben. Die Geschlechtskontrolle durch genetische Tests wurde in den 1960er Jahren ein Thema, als Gerüchte kursierten, dass Männer sich als Frauen ausgeben und an Frauenwettkämpfen teilnehmen. Trotz langjähriger intensiver Kritik werden bis heute genetische Analysen zur Geschlechtsbestimmung im Sport eingesetzt. Dabei müssen jedoch nur Frauen, nicht aber Männer, ihr Geschlecht überprüfen lassen und leiden unter den möglichen Folgen eines »nicht bestandenen« Geschlechtstests. Zwar verzichten inzwischen fast alle Internationalen Olympischen Vereinigungen auf solche Nachweisverfahren, aber bei Weltmeisterschaften wird in einigen Sportarten das Geschlecht weiterhin genetisch »geprüft«. So mussten sich etwa bei der Volleyball-Weltmeisterschaft 2002 in Deutschland alle Frauen einer Genanalyse unterziehen, für die noch kein Testergebnis aus einem vorangegangenen sportlichen Wettkampf vorlag (Simpson et al. 2000; Dickinson et al. 2002; s. a. Lemke 2004c). ${ }^{11}$

Ein personenzentrierter und fallorientierter Diskriminierungsbegriff ist nicht in der Lage, die systematischen Verbindungen zwischen rassistischen und sexistischen Praktiken und Denkweisen auf der einen und genetischen Deutungs- und Handlungsmustern auf der anderen Seite zu untersuchen. Bei genetischer Diskriminierung handelt es sich nicht um isolierte und zufällige Abweichungen von der Norm, um individuelle Fälle und institutionelle Fehlentwicklungen, sondern um geregelte soziale Praktiken, die Menschen in genetische Kategorien einteilen und den Glauben an die determinierende Kraft der Gene fördern. Leider bestimmen Vorstellungen eines genetischen Essentialismus jedoch häufig auch die Analyse und Kritik genetischer Diskriminierung, was zu konzeptionellen Konfusionen auf der einen und normativen Ambivalenzen auf der anderen Seite führt.

10) $\mathrm{Zu}$ der zunehmenden Berücksichtigung der Kategorie »Rasse« in der Genomforschung s. Bradby 1996; Ellison/ Jones 2002, Aldhous 2002; Jacoby 2002; Alper/ Beckwith 2002; Blech 2004; Nature Genetics 2004.

Die Gefahr einer Verbindung von genetischer Diskriminierung und Rassismus ist freilich nicht auf den klinischen Bereich beschränkt. Eine rassistische Diskriminierung kann sich auch aus dem Einsatz genetischer Daten für die Strafverfolgung ergeben, worauf der Erfinder des »genetischen Fingerabdrucks«, Sir Alec Jeffreys, hinweist. Jeffreys äußert sich besorgt angesichts der immer umfangreicheren DNA-Datenbank der britischen Polizei, die inzwischen 2,5 Millionen Datensätze enthält. Darunter befinden sich nicht nur DNA-Proben von Straftätern, sondern auch genetische Informationen von Verdächtigen. »For a start, we are now putting not just criminals but suspects in our database, and this is clearly very highly discriminatory. If you go to certain places such as South London, you will get suspects who are predominantly black. Similarly you will get a lot of Asian suspects in Birmingham. « Die Folge sei, dass die nationale Datenbank mit einer großen Zahl von Schwarzen und Menschen asiatischer Herkunft gefüllt werde, die nicht verurteilt sind, von denen man aber annimmt, dass sie in Zukunft Verbrechen begehen werden (McKie 2004; Cole 2001:287-311, Wasserman/ Wachbroit 2001).

11) Dazu erklärte Albert Fromme, der Leiter des Medizin-Ressorts des Münsteraner Organisationskomitees für die Volleyball-Weltmeisterschaft: »Für die Spielerinnen ist dies eine Form der Diskriminierung. Männer müssen ihre Männlichkeit nicht beweisen« (zit. nach Sport 1, 2002). 


\section{Konzeptionelle Konfusionen: die epistemologische Sonderstellung genetischer Informationen}

Die wissenschaftlichen Untersuchungen zu genetischer Diskriminierung gehen ebenso wie die gesetzgeberischen Initiativen zum Schutz Betroffener von einer gemeinsamen Voraussetzung aus: der Annahme einer doppelten Sonderstellung genetischer Informationen (Alper/ Beckwith 1998). Erstens wird die Auffassung vertreten, dass genetische Informationen sich in epistemologischer Hinsicht von nichtgenetischen Informationen unterscheiden. In dieser Perspektive existiert eine eindeutige wissenschaftliche Grenze, die Gentests von nichtgenetischen Untersuchungen, genetische Krankheiten von nichtgenetischen Leiden trennt. Zweitens seien genetische Informationen normativ von nichtgenetischen Informationen abzugrenzen: Diskriminierung auf der Grundlage genetischer Daten über den gegenwärtigen oder zukünftigen Gesundheitsstatus einer Person ist demzufolge ungerecht oder ungerechter im Vergleich zur Diskriminierung aufgrund nichtgenetischer medizinischer Informationen. Wie im Folgenden gezeigt werden soll, sind jedoch beide Annahmen unhaltbar. Im Mittelpunkt dieses Abschnitts steht die Begründung einer epistemologischen »Sonderstellung « (Schmidtke 1997:96) genetischer Informationen, im nächsten soll dann den normativen Problemen nachgegangen werden, die sich daraus ergeben.

\subsection{Genetischer Exzeptionalismus}

Es gibt mindestens drei Argumente, die angeführt werden, um eine (medizinische) Ausnahmestellung genetischer Tests zu begründen. Genetische Analyseverfahren seien erstens präziser als andere medizinische Tests, da sie prädiktive Informationen über den Gesundheitsstatus eines Individuums liefern. Sie erlaubten $\mathrm{zu}$ bestimmen, ob ein Individuum mit Sicherheit oder einer erhöhten Wahrscheinlichkeit an einem konkreten Leiden erkranken wird. Zweitens ermöglichten die Ergebnisse genetischer Tests Rückschlüsse über den Gesundheitszustand oder die Krankheitsrisiken von Verwandten des untersuchten Individuums. Genetische Tests sollen sich drittens von traditionellen diagnostischen Techniken und konventionellen medizinischen Nachweisverfahren unterscheiden, da sie grundlegende persönliche Charakteristika der Untersuchungsperson offenbarten. Alle drei Unterscheidungskriterien, die zur Begründung eines »genetischen Exzeptionalismus« (genetic exceptionalism) angeführt werden, halten jedoch einer näheren Überprüfung nicht stand (Murray 1997; s.a. Alper/ Beckwith 1998:143 f.; Paul 1999:160; European Commission 2004:44).

Erstens erlauben die wenigsten genetischen Tests prädiktive Aussagen hinsichtlich künftiger Erkrankungen. Genetische Krankheiten zeichnen sich in der Regel durch eine unvollständige Penetranz und/oder eine variable Expressivität aus. Erstere bezieht sich auf die Häufigkeit, mit der eine genetische Mutation bei ihren Trägern tatsächlich die entsprechende Krankheit auslöst. Bei komplexen Erkrankungen wie Krebs, Alzheimer oder Diabetes führt die Anwesenheit eines veränderten Gens nicht notwendigerweise zur Krankheit. So erhöht der Nachweis einer Mutation der BRCA-Gene zwar die statistische Wahrscheinlichkeit, dass eine Frau an Brustkrebs erkrankt, ob, wann und in welcher Weise sie von der Krankheit betroffen sein wird, ist jedoch völlig offen (Feuerstein/ Kollek 2000; Lemke 2004a:70-76). Wie neuere Untersuchungen zeigen, weisen sogar monogenetische Erkrankungen wie Mukoviszidose oder Morbus Huntington keine 100\%ige Penetranz auf (s. Kerr 2000; Van den Boer-van den Berg/ Maat-Kievit 2001).

Variable Expressivität bezieht sich auf den Umstand, dass die Symptome derselben Krankheit bei zwei Individuen außerordentlich differieren können, obwohl beide das gleiche mutierte Gen besitzen. Mit anderen Worten: Dieselbe DNA-Mutation kann ganz unterschiedliche klinische Symptome hervorrufen - oder gar keine; umgekehrt kann dieselbe Krankheit von verschiedenen genetischen Variationen herrühren (Hubbard/ Lewontin 1996; 
Wolf 1997). Aber es ist nicht nur festzuhalten, dass der prädiktive Wert genetischer Informationen regelmäßig überschätzt wird, hinzu kommt, dass auch nichtgenetische medizinische Tests Informationen über zukünftige Gesundheitsrisiken liefern wie der HIV-Test, die Cholesterin-Untersuchung oder der Nachweis einer asymptomatischen Hepatitis B-Infektion. Ebenso sind der Blutdrucktest oder der Nachweis von Blut im Stuhl von großer diagnostischer Bedeutung, um Krankheiten in ihrem Frühstadium zu erkennen, bevor erste Symptome von koronarer Herzkrankheit oder Darmkrebs auftreten (Murray 1997:64; Zimmern 1999; European Commission 2004:44).

Was das zweite Unterscheidungskriterium angeht, so fällt es auch in diesem Fall schwer, die medizinische Einzigartigkeit oder auch nur Besonderheit genetischer Analysen anzuerkennen. Wie Murray zu Recht hervorhebt, war Menschen schon lange bekannt, dass ihr eigenes Risiko für eine Krankheit steigt, falls diese bereits in der Familie aufgetreten ist. Ebenso griffen Ärzte schon in der Vergangenheit auf Informationen über Angehörige zurück, um das medizinische Wissen über ihre Patienten zu ergänzen. Darüber hinaus wird die Familiengeschichte seit geraumer Zeit für Versicherungsverträge bzw. die Bestimmung der Prämienhöhe herangezogen. Genetische Tests sind also weder die einzigen noch die wichtigsten Instrumente, medizinische Daten von Angehörigen zu nutzen, um Aussagen über den Gesundheitsstatus eines Individuums zu treffen (Murray 1997:65).

Die dritte Unterscheidungslinie differenziert zwischen schicksalhaften und unveränderlichen genetischen Anlagen einerseits und zufälligen und kontrollierbaren Umweltfaktoren andererseits. Sie beruht auf der Vorstellung, dass Genen Autonomie und Aktivität zukommt und sie eine Art von Schaltzentrale bilden, die den Organismus steuert und reguliert. Diese Annahme ist in doppelter Hinsicht zumindest grob vereinfachend, wenn nicht irreführend oder falsch. Zunächst sind Gene keine statischen Einheiten, sondern integrale Bestandteile eines komplizierten biochemischen Netzwerks, das sich durch ein dynamisches Zusammenspiel von interdependenten Akteuren auszeichnet (s. Keller 2001; 2002). Daher ist es eine unzulässige Vereinfachung anzunehmen, ein Merkmal oder eine Funktion sei zu einem Anteil erblich und der Rest durch Einflüsse der Umwelt bestimmt. Nicht berücksichtigt wird dabei, dass Genveränderungen auch erst im Laufe des Lebens durch Einflüsse der Umwelt und der Lebensweise erworben werden können. ${ }^{12}$ Darüber hinaus besteht keine einfache Gleichung zwischen genetischer Kausalität und unvermeidlichem Schicksal bzw. nichtgenetischen Faktoren und individueller Entscheidungsfreiheit. Weder signalisieren genetische Krankheitsursachen notwendig biologisches Schicksal noch sind nichtgenetische Bedingungen prinzipiell leichter als genetische zu kontrollieren oder das Resultat individueller Wahlentscheidungen, die selbst zu verantworten sind. ${ }^{13}$ Im Gegenteil gibt es auch viele nichtgenetische Faktoren, über die wir als Einzelne keinerlei Kontrolle besitzen: »If the air we breathe and the water we drink are polluted, if our parents or co-workers are heavy smokers, if we are reasonably prudent but injured in an accident nonetheless, it is hard to say that we bear any significant measure of responsibility for the resulting illness« (Murray 1997:65 f.; Geetter 2002). ${ }^{14}$

12) Die Theorie der Entwicklungssysteme (Developmental Systems Theory) zeigt, dass eine starre Gegenüberstellung von Kultur und Natur zur Erklärung biologischer Prozesse unzureichend ist. Sie geht von der Annahme aus, dass biologische Eigenschaften keineswegs auf einen kulturunabhängigen und überhistorischen Wesenskern verweisen, sie sind Ergebnis, nicht Ursache von Entwicklungsprozessen innerhalb eines komplexen Systems, in dem auch soziale und psychologische Faktoren eine wichtige Rolle spielen. Dieses Forschungsprogramm bricht sowohl mit biologischen wie sozialen Spielarten des Determinismus (Oyama 2000; s.a. Fausto-Sterling 2003).

13) Auf diesen Punkt komme ich weiter unten zurück.

14) Zum Verhältnis von Gesundheit und Verantwortung s. Reiser 1985; Brand/ Rozin 1997. 
Alle drei angeführten Kriterien, die eine (medizinische) Sonderstellung genetischer Informationen begründen sollen, können also nicht überzeugen. Allerdings ist nicht nur die Grenze zwischen genetischen und nichtgenetischen Faktoren diffus, darüber hinaus ist auch unklar, was »genetisch « genau meint. Mit anderen Worten: Es handelt sich nicht um ein definitorisches Problem, das in einer unzulässigen Vermischung oder einer irrtümlichen Verschiebung der Grenze zwischen zwei an sich deutlich unterscheidbaren Komponenten (genetisch/nichtgenetisch) besteht; vielmehr haben wir es hier mit einem systematischen Problem zu tun, das in der »Natur« der Sache liegt. Was jeweils als »Gen«bzw. »genetisch« bezeichnet wird, zeichnet sich durch eine große semantische Flexibilität aus und ist abhängig von wissenschaftlichen Definitionen und sozialen Kontexten (s. Kay 2002; Moss 2003; Lemke 2004b).

\subsection{Genetisch oder nichtgenetisch?}

Das Konzept der genetischen Krankheit ist in den letzten Jahrzehnten immer weiter ausgedehnt worden und hat zugleich eine Redefinition erfahren. Zum einen werden genetische Faktoren nicht nur für »monogenetische« Krankheiten (die so genannten Erbkrankheiten), sondern auch multifaktorielle Erkrankungen wie Krebs, Alzheimer, Diabetes und viele andere weit verbreitete Krankheiten verantwortlich gemacht. Zum anderen wird diese semantische Expansion von einer Bedeutungsverschiebung begleitet, sodass Krankheiten zunehmend als genetische Normabweichungen begriffen werden. Allerdings: Wenn potenziell jede Krankheit auf genetische Veränderungen zurückgeführt wird, ist fraglich, worin der Beitrag genetischer Faktoren genau besteht bzw. wie genetische Krankheitsursachen von nichtgenetischen abzugrenzen sind (Yoxen 1984; Lemke 2003). ${ }^{15}$

Es ist nicht nur unmöglich, abschließend und verbindlich zu definieren, was eine genetische Krankheit im Unterschied zu einem nichtgenetischen Leiden kennzeichnet; darüber hinaus ist auch unklar, wie sich genetische von nichtgenetischen Analysen trennscharf unterscheiden lassen. »Genetische Diagnostik « bezeichnet als Sammelbegriff sämtliche Möglichkeiten der Diagnose genetisch bedingter Krankheiten und Merkmale. Darunter fallen neben Tests auf DNA-Ebene auch phänotypische Diagnosen (wie der Test auf die - genetische bedingte Rot-Grün-Blindheit), Chromosomenuntersuchungen und Analysen auf Genproduktebene (Zimmern 1999; Schmidtke/ Sperling 2003).

Joseph S. Alper und Jon Beckwith machen zu Recht darauf aufmerksam, dass diese umfassende Definition genetischer Tests praktisch jedes klinische Nachweisverfahren einschließt. Sie weisen darauf hin, dass die meisten medizinischen Tests auf die Diagnose abnormaler Konzentrationen von biochemischen Einheiten zielen. Typischerweise sind diese Einheiten Proteine, die direkt von Genen hervorgebracht werden, oder Moleküle, deren Synthese in mehr oder weniger großem Ausmaß von der Aktivität der Gene beeinflusst wird.

15) Murray spricht von einer »two-bucket theory of disease «, welche letztlich dem Irrtum aufsitze, es sei medizinisch eindeutig zwischen genetischen und nichtgenetischen Krankheiten bzw. Krankheitsfaktoren zu unterscheiden: »According to this model, there are two buckets - one labeled >genetic <, the other labeled ,nongenetic $<$ - and we should be able to toss every disease and risk factor into one of the two. So, Huntington disease goes into the >genetic < bucket and getting run over by a truck goes into the >nongenetic $<$ one. But many diseases and risks don't fit neatly into either bucket. Take breast cancer. Some cases of breast cancer have strong genetic roots, but others have no clear genetic connection. For that matter, not every woman with a mutated BRCA1 gene will develop breast cancer. And some apparent risk factors have little or no link to genetics. Similar complexity exists for heart disease: cholesterol is a risk factor, and one's cholesterol level can be modified by diet, exercise, and other factors; but our genes have as much or more to do with the level of cholesterol circulating in our blood as our environment or behavior. Into which bucket, then, should we toss breast cancer? Heart disease? Cholesterol level?« (Murray 1997:67 f.). 
Daher kann ein auffälliger biochemischer Befund von einem veränderten Gen oder Genotyp herrühren. Selbst wenn diese nichtgenetischen Tests also darauf abzielen, die Funktion verschiedener Organe zu bestimmen, liefern sie möglicherweise zugleich Informationen über genetische Charakteristika. Hinzu kommt, dass in manchen Fällen allein der medizinische Kontext darüber entscheidet, ob es sich um einen genetischen oder um einen nichtgenetischen Test handelt: »A test of blood cholesterol concentration may be regarded as genetic when testing an individual with a family history of hypercholesterolemia, a single gene recessive disorder. The same test is clearly a nongenetic medical test when ordered in the course of a routine physical examination « (Alper/ Beckwith 1998:145; Beckwith/ Alper 1998:207). ${ }^{16}$

Daraus folgt, dass sich (mono-)genetische Erkrankungen nicht ausschließlich mit den Mitteln genetischer Tests (genauer: der DNA-Diagnostik) nachweisen lassen. Konventionelle Untersuchungstechniken können in vielen Fällen zuverlässig ein genetisches Leiden feststellen. Dass die Unterscheidung zwischen genetischen und anderen medizinischen Analyseverfahren keine technische Angelegenheit ist, zeigt etwa die Geschichte des PKU-Tests, die Diane Paul rekonstruiert hat. PKU ist eine Stoffwechselerkrankung, bei der ein Enzymdefekt verhindert, dass die Aminosäure Phenylalanin in Tyrosin umgebaut wird. Durch eine spezielle Diät im Kindesalter lässt sich diese Störung jedoch weitgehend kompensieren. Als der sog. Guthrie-Test in den 1960ern entwickelt und zur Diagnose der Krankheit bei Neugeborenen eingesetzt wurde, spielte die genetische Dimension der Krankheit keine Rolle; vielmehr wurde PKU damals als eine behandelbare Form von geistiger Behinderung betrachtet. Zudem handelt es sich bei dem Nachweisverfahren um einen biochemischen Test, nicht um eine Untersuchung auf DNA-Ebene. ${ }^{17}$ Erst wesentlich später wurde der Guthrie-Tests als genetischer Test und PKU als eine genetische Krankheit betrachtet - eine Charakterisierung, die unterschiedlichen Interessen gleichermaßen diente. Die Visionäre einer molekularen Medizin konnten mit dem Hinweis auf den PKU-Test zeigen, dass es Gentests mit therapeutischem Nutzen gibt. Aber auch die Kritiker von Genanalysen profitierten vom Label »genetischer Test«. Im Rahmen des Humangenomprojekts wurden in den USA und anderen Staaten Kommissionen eingesetzt, um speziell genetische Analysen (im Unterschied zu anderen medizinischen Tests) zu regulieren. Da Gentests größerer technischer Sorgfalt und intensiveren rechtlichen Regelungen unterliegen als andere Untersuchungsverfahren, war die Definition des PKU-Tests als genetischer Test auch für Kritiker eines genetischen Determinismus interessant, die der zunehmenden Nutzung von Genanalysen skeptisch gegenüber standen (Paul 1999; zur Geschichte von PKU s. Paul 1998).

Offenbar ist es nicht nur schwierig, genetische von nichtgenetischen Krankheiten wissenschaftlich präzise zu unterscheiden, auch die Grenze zwischen genetischen und nichtgenetischen Tests lässt sich nicht technikimmanent bestimmen, sondern bleibt letztlich abhängig von sozialen Aushandlungsprozessen. Diese Einsicht hat wichtige Folgen für politische Initiativen, welche die Verwendung genetischer Daten in einer speziellen AntidiskriminierungsGesetzgebung zu regeln versuchen.

16) Zimmern (1999:152) hat darauf hingewiesen, dass der Begriff der genetischen Information zwei gegensätzliche Bedeutungen besitzt: »First it may be regarded as information about the genetic constitution of individuals, their genes or chromosomes, and their inheritance. Second, and by contrast, genetic information may be taken to refer to any information from which we may infer knowledge about the genetic constitution of individuals. «

17) Bei dem Guthrie-Test wird ein blutgetränktes Filterpapier auf eine mit Bakteriensporen behandelte Platte aufgebracht. Das Bakterienwachstum ist durch den Zusatz von Betathienylalain zum Nährboden gehemmt und kann nur bei einem bestimmten Phenylalaningehalt der Blutprobe erfolgen (s. Pschyrembel 1999). 


\section{Normative Ambivalenzen: die rechtlich-moralische Privilegierung genetischer Informationen}

Richtet sich eine Diskriminierung aufgrund genetischer Faktoren gegen »asymptomatisch Kranke« (Billings et al. 1992), so trifft eine Ungleichbehandlung auf der Basis phänotypischer Merkmale symptomatisch Kranke. In der Regel wird jedoch Erstere als moralisch und rechtlich problematischer angesehen als Letztere, was in doppelter Hinsicht zu einer Hierarchisierung von Betroffenengruppen führt. Zum einen werden genetische und nichtgenetische Diskriminierung rechtlich unterschiedlich behandelt, was die Frage nach den Kriterien aufwirft, die solche Ungleichbehandlung von Menschen rechtfertigt, die gleichermaßen von diskriminierenden Praktiken betroffen sind. Zum anderen besteht die Gefahr, dass das spezielle Unwerturteil und die rechtlich herausgehobene Praxis genetischer Diskriminierung alle nichtgenetischen Formen von Diskriminierung »normalisiert«. Werden Behinderte und Kranke in den verschiedensten gesellschaftlichen Bereichen regelmäßig gegenüber Gesunden diskriminiert, so scheint dies in dem Maße legitim, in dem ein besonderer Schutz für Menschen existiert, die speziell von Praktiken genetischer Diskriminierung betroffen sind. ${ }^{18}$ Mit anderen Worten: Die Konzentration auf die rechtliche Unzulässigkeit und moralische Verwerflichkeit genetischer Diskriminierung setzt verschiedene Diskriminierungsformen voneinander ab, spielt sie gegeneinander aus und erhöht tendenziell die gesellschaftliche Akzeptanz für Praktiken nichtgenetischer Diskriminierung.

Gregor Wolbring (2001:87 f.) hat darauf hingewiesen, dass prinzipiell zwei völlig unterschiedliche rechtspolitische Strategien denkbar sind, um die Diskriminierung asymptomatisch Kranker zu verhindern. Der eine Weg könnte darin bestehen, die existierenden Behindertengleichstellungs- und Antidiskriminierungsgesetze so zu erweitern und auszubauen, dass sie Diskriminierungen gegen asymptomatisch und symptomatisch, genetisch und nichtgenetisch Kranke gleichermaßen erfassen. In den USA und in vielen anderen Ländern wird jedoch gegenwärtig ein anderer Weg beschritten, der spezielle Gesetze zum Schutz asymptomatisch Kranker vorsieht. Grundlage dieser Gesetze bzw. der Gesetzesinitiativen, die derzeit verhandelt werden, ist eine strikte und eindeutige Unterscheidung zwischen asymptomatisch und symptomatisch Kranken. Wolbring macht darauf aufmerksam, dass auf diese Weise die rechtliche Kluft zwischen beiden Betroffenengruppen vergrößert wird. Statt genetische Diskriminierung als integralen Bestandteil eines allgemeinen Kontinuums von Diskriminierungspraktiken zu begreifen, soll sie eine spezifische Zäsur markieren, die konzeptionell und normativ von anderen Formen der Benachteiligung zu trennen sei. Wie Wolbring zu Recht bemerkt, ist jedoch fraglich, ob es eine Diskriminierung gegen asymptomatisch Kranke ohne die Diskriminierung symptomatisch Kranker und Behinderter gäbe (Wolbring 2001:87).

Bezeichnenderweise finden sich Differenzen in der rechtlich-moralischen Beurteilung von Diskriminierungspraktiken nicht nur zwischen symptomatisch und asymptomatisch Kranken, sondern auch innerhalb der Gruppe der asymptomatisch Kranken. Dabei wird zwischen Menschen unterschieden, die von genetischen Risiken und solchen, die von nichtgenetischen Krankheitsrisiken betroffen sind. Gemeinsam ist beiden, dass sich die Krankheit noch nicht manifestiert hat, und möglicherweise niemals auftreten wird, die rechtliche Einschätzung und Bewertung der Risiken fallen jedoch ganz unterschiedlich aus. Eine Gegenüberstellung von zwei ähnlich gelagerten Fällen, die fast zeitgleich im selben Bundesland stattfanden, soll dieses Problem illustrieren.

18) S. etwa Rothblatt 1997:157: »If we have a genomic predisposition to a particular condition that interferes with our job ability, then it is wrong to deny that job until the condition manifests itself.« 


\section{1 »n die Wiege gelegt« - Die Wiedergeburt des genetischen Essentialismus als Antidiskriminierungspolitik}

Der erste Fall fand kürzlich ein breites Medienecho und sorgte im In- und Ausland für erhebliches Aufsehen (Mechan-Schmidt 2003; Burgermeister 2003; Traufetter 2003). Einer Lehrerin wurde im August 2003 die Einstellung als Beamtin auf Probe in den hessischen Schuldienst verweigert. Die junge Frau hatte auf Nachfrage der Amtsärztin angegeben, dass ihr Vater an Morbus Huntington leide. ${ }^{19}$ Das amtsärztliche Gutachten kam zwar zu dem Ergebnis, dass zum gegenwärtigen Zeitpunkt eine gesundheitliche Eignung der Bewerberin vorliege; die Verbeamtung wurde dennoch mit der Begründung abgelehnt, dass eine erhöhte Wahrscheinlichkeit bestehe, dass sie in absehbarer Zukunft erkranken und dauerhaft dienstunfähig werde. Die Bewerberin klagte gegen diese Entscheidung vor dem Verwaltungsgericht Darmstadt, das ihr weitgehend Recht gab und das Land verpflichtete, sie umgehend in das Beamtenverhältnis zu berufen. Nach Ansicht des Gerichts hatte die Schulbehörde die gesundheitliche Eignung der Beamtenanwärterin falsch beurteilt, da sie das Erkrankungsrisiko von 50 Prozent als »überwiegende Wahrscheinlichkeit« einer dauerhaften Dienstunfähigkeit bewertet habe. Das Schulamt verzichtete auf weitere Rechtsmittel und übernahm die Frau inzwischen in den Staatsdienst (Frankfurter Rundschau 2004a). ${ }^{20}$

Zur gleichen Zeit fand ein anderer Rechtsstreit wesentlich weniger öffentliche Aufmerksamkeit. Ein junger Mann wurde ebenfalls in Hessen aus dem Beamtenverhältnis auf Probe entlassen, da er nach Ansicht seines Dienstherrn mit 120 kg Körpergewicht gesundheitlich nicht für eine Laufbahn in der allgemeinen Verwaltung geeignet sei. Auch in diesem Fall reichte der Betroffene Klage gegen die Entscheidung ein. Das Verwaltungsgericht Frankfurt bestätigte jedoch in seinem Urteilsspruch, dass die Entlassung rechtmäßig sei, da der Dienstherr dem Risiko vorbeugen dürfe, für spätere dauerhafte Gesundheitsschäden aufkommen zu müssen (Frankfurter Rundschau 2004b). Obwohl der Bewerber also nicht erkrankt war und völlig unsicher ist, ob und in welcher Weise sein erhöhtes Körpergewicht in Zukunft seine Gesundheit beeinträchtigt, wurde er rechtlich behandelt, als sei er bereits dienstunfähig.

Die Beispielfälle zeigen, dass die Unterscheidung zwischen genetischen und nichtgenetischen Informationen nicht als Basis einer rechtlichen Differenzierung taugt. Erstens ist nicht nachvollziehbar, warum etwa der Einsatz von biochemischen Verfahren, die Rückschlüsse auf genetische Dispositionen ermöglichen, für diskriminatorische Zwecke erlaubt, der Einsatz von DNA-Tests, die zum selben Ergebnis kommen, hingegen verboten sein soll. Es erscheint nicht nur wenig praktikabel, sondern auch unfair, die Verwertung einer genetischen Analyse für eine komplexe Erkrankung etwa durch eine Versicherungsgesellschaft zu untersagen, während die Ergebnisse eines nichtgenetischen Tests für dieselbe Krankheit berücksichtigt werden dürfen. Dieses Vorgehen führt im Ergebnis zu einer Rechtslage, in der Menschen mit positiven genetischen Diagnosen mehr Schutz vor Diskriminierung und Datenmissbrauch genießen als solche, deren Untersuchungsbefund sich auf nichtgenetischen Nachweisverfahren stützt: »Would the law mean that the records of a person with a presymptomatic heart condition who was given a genetic test for some mutant gene associated with heart disease would be covered by antidiscrimination provisions, but not the records of a person with the same condition whose physician order only nongenetic tests? « (Alper/ Beckwith 1998:147; Zimmern 1999:153).

19) Bei der Huntington-Krankheit handelt es sich um eine neurodegenerative Erkrankung, die meist erst im vierten oder fünften Lebensjahrzehnt zum Ausbruch kommt. Sie wird hervorgerufen durch eine erhöhte Wiederholung eines bestimmten Tripletts (Abfolge der drei Kernbasen Cytosin, Adenin, Guanin: CAG) im Huntingtin-Gen, das auf dem kurzen Arm von Chromosom 4 lokalisiert ist (Lange 2002).

20) Urteil des Verwaltungsgerichts Darmstadt vom 24. Juni 2004, AZ 1 E 470/04 (3). 
Zweitens bleibt unverständlich, warum es institutionellen Akteuren wie Versicherungen oder Arbeitgebern verboten sein soll, eine Quelle genetischer Information - Genanalysen zu nutzen, während es ihnen erlaubt ist, andere Formen genetischen Wissens heranzuziehen. So ist es nach dem Entwurf des Bundesgesundheitsministeriums für ein Gendiagnostikgesetz einer Versicherungsgesellschaft untersagt, von einer Frau mit einem positiven Ergebnis eines BRCA-Tests auf Brustkrebs eine höhere Versicherungsprämie zu verlangen, während dies zulässig sein soll gegenüber einer Frau, die es vorzog, keinen genetischen Test zu machen, in deren Familie aber bereits mehrere Frauen an Brustkrebs erkrankt sind (s. Geetter 2002). Durch dieses asymmetrische Entscheidungsprinzip wird nicht nur das Gebot der Fairness verletzt, es ist darüber hinaus zu befürchten, dass durch eine solche Regelung Menschen dazu gedrängt werden, sich genetischen Analysen zu unterziehen, auch wenn sie dies zunächst gar nicht wollten - etwa um Versicherungen (zu Standardkonditionen) zu erhalten. ${ }^{21}$

Drittens dürfte die zunehmende Entdeckung genetischer Faktoren für die Krankheitsgenese eine Abgrenzung zwischen genetischen und nichtgenetischen Leiden in Zukunft immer schwieriger machen. Auf den oben angeführten Fall bezogen, könnte man etwa eine Reihe von Forschungsarbeiten anführen, die eine genetische Komponente von Fettsucht nachzuweisen versuchen (s. Shell 2002; Hebebrand 2004). Wie würde das Urteil ausfallen, wenn der Bewerber glaubhaft machen könnte, dass eine bestimmte genetische Disposition für sein Übergewicht (mit-)verantwortlich ist? Hätten wir es dann mit einer genetischen Diskriminierung zu tun, deren Betroffene einen besonderen Schutz genießen?

Zusammenfassend lässt sich feststellen, dass der Akzent der Antidiskriminierungspolitik offenbar eher auf der (genetischen) »Natur« der Informationen liegt als auf den sozialen Praktiken, in denen diese Daten eingesetzt und verwertet werden (s. dazu auch Wolf 1995). Die Gesetze zum Schutz vor genetischer Diskriminierung sind nicht zuletzt von der impliziten Vorstellung getragen, dass Gene menschliche Existenz in fundamentaler Weise prägen und sie den Kern der Persönlichkeit ausmachen. In dieser Perspektive ist es unfair, Menschen für etwas zu bestrafen, das sie nicht selbst kontrollieren könnten. ${ }^{22}$ Diese Argumentationslogik findet sich auch in der Begründung des Bundesgesundheitsministeriums für das geplante Gendiagnostikgesetz. Jeder Form einer genetische Diskriminierung - so heißt es dort - sei entgegenzutreten: »Denn die genetischen Eigenschaften sind dem Menschen >in die Wiege gelegt< und daher von diesem nicht zu verantworten« (Bundesministerium für Gesundheit und Soziale Sicherung 2004:16). ${ }^{23}$ Diese Forderung scheint zunächst plausibel, ist aber bei genauerem Hinsehen wenig überzeugend. Dahinter verbirgt sich die Idee eines genetischen Programms, das für die Entwicklung und Identität der Individuen »verantwortlich«

21) Ein gesetzliches Verbot genetischer Diskriminierung dürfte auch zu einer weiteren Kommerzialisierung des Gendiagnostiksektors führen bzw. diese erst ermöglichen. So fordert etwa der Präsident und Medizinische Leiter des US-amerikanischen Gendiagnostikanbieters myDNA, William Rice, nachdrücklich ein bundesstaatliches Antidiskriminierungsgesetz, da nach seiner Einschätzung die meisten Bürger ohne den Schutz genetischer Privatheit genbasierte Tests meiden werden, um Diskriminierung bei Arbeitsverhältnissen und Versicherungsverträgen zu verhindern (Yahoo Financial News 2004). Ähnlich äußerte sich in Deutschland der Verband der Diagnostica-Industrie in einer Pressemitteilung, die für das geplante Gendiagnostikgesetz wirbt (s. Görlitzer 2004).

22) Dieses Argument kennzeichnet auch viele wissenschaftliche Arbeiten, die sich kritisch mit Praktiken genetischer Diskriminierung auseinander setzen. S. etwa Gostin 1991:110 f.: »Prejudice, alienation and exclusion often accompany genetically related diseases even though, by definition, the condition is neither subject to the person's control, nor the result of willful behavior.« Ebenso Rothblatt 1997:157: »Genomic discrimination is wrong because it categorizes us on the basis of biology over which we have no control and which is irrelevant for any social, economic, or legal purpose."

23) Vgl. die Bemerkung der Bundesjustizministerin Zypries, das Erbgut sei »das Wertvollste, was der Mensch hat« (zit. nach Schwingerl 2005, S. 4). 
ist und deren Handlungsmöglichkeiten zugleich konstituiert und beschränkt. Es ist die Annahme einer besonderen Wirkmächtigkeit und Autonomie genetischer Faktoren, die deren privilegierten rechtlichen Status begründet. Prinzipiell existieren jdeoch viele nichtgenetische Faktoren, die sich ebenso der individuellen Kontrolle entziehen, ohne eine spezifische Schutzwürdigkeit reklamieren zu können. Es ist keineswegs einsichtig, warum eine Person, deren erhöhtes Erkrankungsrisiko etwa für eine bestimmte Krebsform auf genetische Faktoren zurückgeht, einen größeren Schutz genießen soll als jemand, bei dem die gesundheitliche Gefährdung von Umweltfaktoren wie schlechten Arbeitsbedingungen oder verschmutzter Luft ausgeht. Sollte nicht auch dieser Betroffenenkreis wirksam geschützt werden? (s. Diver/ Cohen 2001:1451 f.).

$\mathrm{Zu}$ vermuten ist, dass die explizite Verantwortungsentlastung im Fall genetischer Krankheitsrisiken die andere Seite einer zunehmenden Verantwortungszuschreibung für alle nichtgenetischen Faktoren markiert. ${ }^{24}$ Der reduktionistischen Konzeption eines Genfatalismus, der sich automatisch und unabhängig von dem Willen der Einzelnen realisieren soll, steht ein radikalisierter Appell an Eigenverantwortung und Eigenvorsorge in Gesundheitsverhalten und Krankheitsprävention gegenüber (Kühn 1998; Bause 2000). Möglicherweise beruhen die unterschiedlichen Urteile in den beiden oben angeführten Fällen auf einer gemeinsamen Begründungslogik, welche die Frage der Verantwortung des Individuums ins Zentrum stellt: Das erhöhte Körpergewicht und die daraus resultierenden Gesundheitsrisiken würden tendenziell als (fehlerhaftes) Resultat individueller Wahlentscheidungen betrachtet, während das Risiko, an Morbus Huntington zu erkranken, als biologisches Schicksal und damit als unverschuldet gilt.

\section{Paradoxien der Kritik}

Die Forderung, genetische Diskriminierung von anderen Diskriminierungsformen abzusetzen und sie einer besonderen Gesetzgebung zu unterwerfen, hat einen paradoxen Effekt. Das Verbot einer »Ungleichbehandlung « von Menschen mit einer »abnormen« genetischen Konstitution, verstärkt den kulturellen Glauben an die Sonderstellung genetischer Faktoren, dem doch eigentlich mit der rechtlichen Regulierung begegnet werden soll. Die Analyse und Kritik genetischer Diskriminierung greift selbst auf das Phantasma zurück, dass die Gene den »Bauplan« eines Individuums und das »Geheimnis des Lebens« bilden. ${ }^{25}$ Die Antidiskriminierungsgesetzgebung droht so jenes Problem zu verschärfen, als dessen Lösung sie sich präsentiert. Damit sind wir mit einem spezifischen Dilemma konfrontiert (s.a. Beckwith/ Alper 1998:208). Auf der einen Seite gibt es Praktiken genetischer Diskriminierung und Menschen, die unter diesen Praktiken leiden; auf der anderen Seite wird der genetischen Essentialismus durch die wissenschaftliche und rechtliche Bekräftigung einer Sonderrolle genetischer Faktoren erneuert und verstärkt.

Aus diesem Dilemma folgt keineswegs, dass gesetzliche Bestimmungen zum Schutz von Menschen mit genetischen Eigenheiten überflüssig oder gar schädlich sind. Im Gegenteil: Selbst wenn genetischen Informationen wissenschaftlich betrachtet keine privilegierte Rolle

24) S.a. Beckwith/ Alper 1998:208: »This rationale seems to carry with it the invidious implication that we are responsible for our nongenetic diseases."

25) Auf ein ähnliches Problem verweist Ingrid Schneider anhand der Debatte um die Patentierung menschlicher Gene: »Indem KritikerInnen und Betroffene jedoch behaupten, ihr Innerstes oder ihr ,Identität< würde mit der Patentierung von Genen geraubt, reproduzieren und bestätigen sie einen genetischen Determinismus und Essentialismus, der menschliches Sein kausalistisch an die DNA kurzschließt« $(1999,15)$. 
gegenüber nichtgenetischen Daten zukommen mag, sie besitzen in der sozialen Realität zweifellos eine herausgehobene Bedeutung. ${ }^{26}$ In kultureller Hinsicht symbolisieren Gene etwas Schicksalhaftes und Unveränderliches (Nelkin/ Lindee 1995; Van Dijck 1998). Sie gelten als »der intimste biologische Besitz, den wir haben « (Schmidtke 1997:13) und sollen die individuelle Lebensführung entscheidend bestimmen (Burnham/ Phelan 2002; Little 2002). Anders als andere Gesundheitsgefahren, die in einem vorübergehenden, behandelbaren und prinzipiell zu beseitigenden Risiko bestehen, sollen Gene die Identität eines Menschen begründen. Er oder sie »trage« oder »besitze« nicht nur genetische Risiken, vielmehr seien diese integraler Bestandteil der eigenen physischen Existenz (s. Kavanagh/ Broom 1998). Werden für eine Krankheit genetische Faktoren verantwortlich gemacht, so erscheint sie den Betroffenen als unkontrollierbar und bedrohlicher als wenn nichtgenetische Ursachen angeführt werden (Senior et al. 1999). Ebenso wenig sind genetische Krankheitsrisiken von der Geschichte der Eugenik zu trennen, von der Erfassung und Ermordung von Menschen, die als »genetisch minderwertig « galten, von einem transgenerationalen Krankheitsbegriff und der Idee »defekter «, »kranker« oder »schlechter« Gene (Holtzman/ Rothstein 1992; Kevles 1995; Markel 1992; Weingart et al. 1992). Solange diese kulturellen Stereotype und historischen Vorurteilsstrukturen weiterbestehen und Menschen aufgrund ihrer genetischen Eigenheiten benachteiligt oder missachtet werden, ist ein gesetzlicher Schutz der Betroffenen unverzichtbar. $^{27}$

Allerdings sollte ein solcher gesetzlicher Schutz nicht darin resultieren, genetische Daten von anderen (prädiktiven) medizinischen Informationen zu isolieren. Genetische Diskriminierung ist das Resultat einer zunehmenden Ausdehnung des Krankheits- und Behinderungsbegriffs und der Erweiterung bestehender Praktiken von Missachtung, Stigmatisierung und Ausschluss. Daher muss das Verbot genetischer Diskriminierung notwendig ergänzt werden durch tiefer greifende institutionelle Reformen und umfassendere Regelungen, die bereits Erkrankte und behinderte Menschen wirksamer vor gesellschaftlicher Ausgrenzung schützen (Alper/ Beckwith 1998:148; Beckwith/ Alper 1998:209; Geetter 2002). Erforderlich ist aber auch, Analyse und Kritik genetischer Diskriminierung im Hinblick auf ihre Prämissen und Zielsetzungen zu überdenken. Sonst besteht die Gefahr, dass die Unterscheidung genetisch/ nichtgenetisch die übergeordnete Frage ausblendet, in welcher Weise (prädiktive) medizinische Informationen allgemein eingesetzt werden, um Menschen zu kategorisieren, ihnen Charakteristika und Merkmale zuzuschreiben und sie von bestimmten Leistungen auszuschließen (s. Wolf 1995). Ohne diese doppelte Selbstaufklärung führt die Kritik genetischer Diskriminierung zu einer weiteren »Genetifizierung « von Körper, Krankheit und Devianz.

26) Dieses Argument wird ausführlich von Deborah Hellman entwickelt: »This article will develop the argument that because the social meaning of treating people differently on the basis of their genetic make-up is different from the social meaning of discrimination on the basis of health or illness, special legislation is warranted to prohibit genetic discrimination « (2003:79; s.a. Murray 1997:71).

27) In diesem Punkt besteht die zentrale Differenz zu der Position von Ulrich Stockter, der herausstellt, dass ein Verbot genetischer Diskriminierung rechtspolitisch kontraproduktiv sei, da es dem genetischen Determinismus Vorschub leiste, den es eigentlich bekämpfen will. Zugleich ist der Autor jedoch der Auffassung, dass "Aussagen anhand von genetischen Merkmalen keine besondere Bedeutung« (2004:41) zukomme, weshalb etwa die Verwendung prädiktiver Daten im Versicherungsbereich zulässig und gerechtfertigt sei. 


\section{Literatur}

Aldhous, Peter (2002): Geneticist fears »race-neutral« studies will fail ethnic groups, in: Nature 418, S. 355-356.

Alper, Joseph S./ Beckwith, Jon (1998): Distinguishing Genetic from Nongenetic Medical Tests: Some Implications for Antidiscrimination Legislation, in: Science and Engineering Ethics 4, S. 141-150.

Alper, Joseph S./ Beckwith, Jon (2002): Genetics, Race, and Ethnicity. in: Joseph S. Alper et al. (Hg.), The Double-Edged Helix. Social Implications of Genetics in a Diverse Society. Baltimore/ London: John Hopkins UP, S. 175-196.

Andrews, Lori B. (2001): Future Perfect. Confronting Decisions About Genetics. New York: Columbia University Press.

Bause, Margarete (2000): Guter Rat ist teuer - humangenetische Beratung unter den Bedingungen der Marktindividualisierung, in: Jörg Schmidtke (Hg.), Guter Rat ist teuer. Was kostet die Humangenetik, was nutzt sie? München/ Jena: Urban \& Fischer, S. 96-106.

Beckwith, Jon/ Alper, Joseph S. (1998): Reconsidering Genetic Antidiscrimination Legislation, in: Journal of Law, Medicine and Ethics 26, S. 205-210.

Beeson, Diane and Duster, Troy (2002): African American Perspectives on Genetic Testing, in: Joseph S. Alper et al. (Hg.) The Double-Edged Helix. Social Implications of Genetics in a Diverse Society. Baltimore und London: The John Hopkins University Press, S. 151-174.

Billings, Paul R./ Kohn, Mel A./ Cuevas de, Margaret/ Beckwith, Jonathan/ Alper, Joseph S./ Natowicz, Marvin R. (1992): Discrimination as a Consequence of Genetic Testing, in: American Journal of Human Genetics 50, S. 476-482.

Blech, Jörg (2004): Die neue Rassendebatte, in: Der Spiegel, Nr. 17, S. 186-188.

Bradby, Hannah (1996): Genetics and racism, in: Theresa Marteau/ Martin Richards (Hg.), The troubled helix: social and psychological implications of the new human genetics. Cambridge: Cambridge UP, S. 295-316.

Brandt, Allan M./ Rozin, Paul (1997): Morality and Health. New York/ London: Routledge.

Bundesministerium für Gesundheit und Soziale Sicherung (2004): Begründung zum Diskussionsentwurf »Gesetz über genetische Untersuchungen bei Menschen«, Berlin.

Burgermeister, Jane (2003): Teacher was refused job because relatives have Huntington's disease, in: British Medical Journal 327: 827-a.

Burnham, Terry/ Phelan, Jay (2002): Unsere Gene. Eine Gebrauchsanleitung für ein besseres Leben. Berlin: Argon.

Canguilhem, Georges (1977): Das Normale und das Pathologische. Frankfurt am Main u.a.: Ullstein.

Cole, Simon A. (2001): Suspect Identities. A History of Fingerprinting and Criminal Identification. Cambridge, MA/ London: Harvard University Press.

Degener, Theresia (1998): Ein behindertes Kind als Schaden? in Gen-Ethischer Informationsdienst, Nr. 129, S. 26-31.

Degener, Theresia/ Köbsell, Swantje (1992): »Hauptsache, es ist gesund «? Weibliche Selbstbestimmung unter humangenetischer Kontrolle. Hamburg : Konkret Verlag.

Deutscher Bundestag (2002): Schlussbericht der Enquete-Kommission »Recht und Ethik in der modernen Medizin«. Opladen: Leske und Budrich.

Dickinson, Barry D./ Genel, M./ Robinowitz, C. B./ Turner, P. L./ Woods, G. L. (2002): Gender Verification of Female Olympic Athletes. Medicine and Science, in: Sports and Exercise 34, S. 1539-1542.

Diver, Colin S./ Cohen, Jane M. (2001): Genophobia: What Is Wrong With Genetic Discrimination? in: University of Pennsylvania Law Review 149, S. 1439-1482.

Duster, Troy (1991): Backdoor to Eugenics. New York/ London: Routledge.

Ellison, George T. H./ Jones, Ian Rees (2002): Social identities and the >new genetics $<$ scientific and social consequences, in: Critical Public Health 12, S. 265-282. 
European Commission (Hg.) (2004): Ethical, legal and social aspects of genetic testing: research, development and clinical applications. Brüssel: EC.

Fausto-Sterling, Anne (2003): The problem with sex/gender and nature/nurture, in: Simon J. Williams/ Lynda Birke/ Gillian A. Bendelow (Hg.), Debating Biology. Sociological reflections on health, medicine and society. New York/ London: Routledge, S. 123-132.

Feuerstein, Günter/ Kollek, Regine (2000): Risikofaktor Prädiktion. Unsicherheitsdimensionen diagnostischer Humanexperimente am Beispiel prädiktiver Brustkrebstests, in: Ludger Honnefelder/ Christian Streffer (Hg.), Jahrbuch für Wissenschaft und Ethik, Band 5. Berlin: De Gruyter, S. 91-115.

Frankfurter Rundschau (2004a): Erblich belastete Lehrerin wird Beamtin, in: Frankfurter Rundschau, 3. August 2004.

Frankfurter Rundschau. (2004b): Zu dick für Beamtenjob, in: Frankfurter Rundschau, 3. Juni 2004.

Geetter, Jennifer S. (2002): Coding for Change: the Power of the Human Genome to Transform the American Health Insurance System, in: American Journal of Law \& Medicine 28, S. 1-76.

Geller, Lisa N. et al. (1996): Individual, Family, and Societal Dimensions of Genetic Discrimination: A Case Study Analysis, in: Science and Engineering Ethics 2, S. 71-88.

Görlitzer, Klaus-Peter (2004): Gentest-Gesetz nach Wünschen von Kassen, Forschern und Firmen, in: Bioskop 7 (Nr. 28), S. 8-9.

Gostin, Larry (1991): Genetic Discrimination: The Use of Genetically Based Diagnostic and Prognostic Tests by Employers and Insurers, in: American Journal of Law \& Medicine 17 (No. 1+2), S. 109-144.

Habermas, Jürgen (2001): Die Zukunft der menschlichen Natur. Auf dem Weg zu einer liberalen Eugenik? Frankfurt am Main: Suhrkamp.

Hall, Mark A./ Rich, Stephen S. (2000): Laws Restricting Health Insurers' Use of Genetic Information: Impact on Genetic Discrimination, in: American Journal of Human Genetics 66, S. 293-307.

Hebebrand, Johannes (2004): Mehr Übergewicht - mehr Krankheiten? Genetische Ursachen der Übergewichtigkeit werden erforscht, in: GenomXPress, Nr. 4, S. 19-21.

Hellman, Deborah (2003): What Makes Genetic Discrimination Exceptional? in: American Journal of Law \& Medicine 29, S. 77-116.

Holtzman, Neil A./ Rothstein, Mark A. (1992): Invited Editorial - Eugenics and Genetic Discrimination, in: American Journal of Human Genetics 50, S. 457-459.

Hubbard, Ruth/ Lewontin, Richard. C. (1996): Pitfalls of genetic testing, in: The New England Journal of Medicine 334, S. 1192-1194.

Jacoby, Petra (2002): Keine Frage der Hautfarbe, in: Spektrum der Wissenschaft, Nr. 6, S. 23-24.

Kavanagh, Anne M./ Broom, Dorothy H. (1998): Embodied Risk: My Body, Myself? in: Social Science \& Medicine 46, S. 437-444.

Kay, Lily E. (2002): Das Buch des Lebens. Wer schrieb den genetischen Code? München: Hanser.

Keller, Evelyn Fox (2001): Das Jahrhundert des Gens. Frankfurt/ New York: Campus.

Keller, Evelyn Fox (2002): Making Sense of Life. Explaining Biological Development with Models, Metaphors, and Machines. Cambridge, MA/ London: Harvard University Press.

Kerr, Anne (2000): (Re)Constructing Genetic Disease: The Clinical Continuum between Cystic Fibrosis and Male Infertility, in: Social Studies of Science 30, S. 847-894.

Kevles, David J. (1995): In the name of eugenics: genetics and the uses of human heredity. Cambridge, MA/ London: Harvard University Press.

Kitcher, Philip (1998): Genetik und Ethik. Die Revolution der Humangenetik und ihre Folgen. München: Luchterhand.

Konrad, Monica (2003): From Secrets of Life to the Life of Secrets: Tracing Genetic Knowledge as Genealogical Ethics in Biomedical Britain, in: Royal Anthropological Institute 9, S. 339-358.

Kühn, Hagen (1998): »Selbstverantwortung « in der Gesundheitspolitik, in: Jahrbuch für kritische Medizin, Nr. 30, S. 7-20. 
Lange, Herwig W. (2002): Morbus Huntington - Klinik, Diagnose und Therapie, in: Psycho 28, S. 479486.

Lapham, Virginia E./ Kozma, C./ Weiss, J. O. (1996): Genetic Discrimination: Perspectives of Consumers, in: Science 274, S. 621-624.

Lemke, Thomas (2003): Molekulare Medizin? Anmerkungen zur Ausweitung und Redefinition des Konzepts der genetischen Krankheit, in: Prokla. Zeitschrift für kritische Sozialwissenschaft 33, S. 471-492.

Lemke, Thomas (2004a): Veranlagung und Verantwortung. Genetische Diagnostik zwischen Selbstbestimmung und Schicksal. Bielefeld: transcript Verlag.

Lemke, Thomas (2004b): Gen, in: Ulrich Bröckling, Susanne Krasmann, Thomas Lemke (Hg.), Glossar der Gegenwart, Frankfurt am Main: Suhrkamp, S. 89-96.

Lemke, Thomas (2004c): Die Gene der Frau. Humangenetik als Arena der Geschlechterpolitik, in: Feministische Studien 22, S. 22-38.

Lemke, Thomas (2005): Genetische Diskriminierung in Deutschland - Eine explorative Studie am Beispiel der Huntington-Krankheit (Manuskript).

Lemke, Thomas/ Lohkamp, Christiane (2005): Formen und Felder genetischer Diskriminierung. Ein Überblick über empirische Studien und aktuelle Fälle, in: Leviathan (im Erscheinen)

Little, Peter (2002): Genetic Destinies. Oxford: Oxford University Press.

Low, Lawrence/ Kind, Suzanne/ Wilkie, Tom (1998): Genetic discrimination in life insurance: empirical evidence from a cross sectional survey of genetic support groups in the United Kingdom, in: British Medical Journal 317, S. 1632-1635.

Luhmann, Niklas (1997): Die Gesellschaft der Gesellschaft. Frankfurt am Main: Suhrkamp.

Markel, Howard (1992). The Stigma of Disease - Implications of Genetic Screening, in: American Journal of_Medicine 93, S. 209-215.

McKie, Robin (2004): Inventor warns over abuse of DNA data, in: Observer, 8. August 2004.

Mechan-Schmidt, Frances (2003): Teacher protests at gene bias, in: Times Educational Supplement, 14. November 2003.

Moss, Lenny (2003): What genes can't do. Cambridge/ MA und London: MIT Press.

Murray, Thomas H.(1997): Genetic Exceptionalism and »Future Diaries«: Is Genetic Information Different from Other Medical Information? in: Mark A. Rothstein (Hg.), Genetic Secrets. Protecting Privacy and Confidentiality in the Genetic Era. New Haven/London: Yale University Press, S. 60-73.

Natowicz, Marvin R./ Alper, J. K./ Alper, J. S. (1992): Genetic Discrimination and the Law, in: American Journal of Human Genetics 50, S. 465-475.

Nature Genetics 2004: >Race< and the human genome, in: Nature Genetics Supplement 36 (November 2004).

Nelkin, Dorothy (1995): Die gesellschaftliche Sprengkraft genetischer Informationen. in: Daniel J. Kevles/ Leroy Hood (Hg.), Der Supercode. Die genetische Karte des Menschen. Frankfurt am Main/ Leipzig: Insel, S. 195-209.

Nelkin, Dorothy/ Lindee, Susan M. (1995):The DNA Mystique. The Gene As a Cultural Icon. New York: W. H. Freemann \& Co.

Neuer-Miebach, Therese (2001): »Genetische Diskriminierung «. in: CDU-Bundesgeschäftsstelle (Hg.), Arbeitsmaterialien Bioethik. Berlin, S. 53-67.

Nowlan, William J. (2003): A Scarlet Letter or a Red Herring? Genetic Discrimination Is of Little Concern Compared With Existing US Healthcare Problems, in: Nature 421 (6921), S. 313.

Otlowski, Margaret F./ Taylor, Sandra D./ Barlow-Stewart, Kristine K. (2002): Australian Empirical Study into Genetic Discrimination, in: Eubios. Journal of Asian and International Bioethics 12, S. 164-167.

Oyama, Susan (2000): The Ontology of Information. Durham/London: Duke University Press.

Paul, Diane B. (1998): PKU Screening: Competing Agendas, Converging Stories. in: Diane Paul, The Politics of Heredity. Essays on Eugenics, Biomedicine, and the Nature-Nurture Debate. Albany: State University of New York, S. 173-186. 
Paul, Diane B. (1999): What Is a Genetic Test, and Why Does It Matter? in: Endeavour 23, S. 159-161.

Pschyrembel (1999): Klinisches Wörterbuch, 258. Auflage, Berlin: De Gruyter (CD-ROM Version)

Reilly, Philip R. (1999): Genetic Discrimination, in: Clarissa Long (Hg.), Genetic Testing and the Use of Information. Washington DC: AEI Press, S. 106-132.

Reiser, Stanley. J. (1985): Responsibility for Personal Health - a Historical-Perspective, in: Journal of Medicine and Philosophy 10, S. 7-17.

Rifkin, Jeremy (2000): Genetische Diskriminierung. Eine neue Form des sozialen Vorurteils, in: Süddeutsche Zeitung, 29. Juni 2000.

Rothblatt, Martine (1997): Unzipped Genes. Taking charge of baby-making in the new millenium. Philadelphia: Temple University Press.

Schmidtke, Jörg (1997): Vererbung und Ererbtes - Ein humangenetischer Ratgeber. Reinbek: Rowohlt.

Schmidtke, Jörg/ Sperling, Karl (2003): Genetische Tests auf dem Teststand, in: Zeitschrift für Biopolitik 2, S. 39-47.

Schneider, Ingrid (1999): Patente Argumente? in: Bioskop, Nr. 8, S. 14-15.

Scholz, Christine (1995): Biographie und molekulargenetische Diagnostik, in: Elisabeth Beck-Gernsheim (Hg.), Welche Gesundheit wollen wir? Dilemmata des medizintechnischen Fortschritts. Frankfurt am Main: Suhrkamp, S. 33-72.

Schwägerl, Christian (2005): Gentests. Prinzip Selbstbestimmung, in: Frankfurter Allgemeine Zeitung, 14. Januar 2005.

Senior, Victoria/ Marteau, T. M./ Peters, T. J.(1999): Will genetic testing for predisposition for disease result in fatalism? A qualitative study of parents responses to neonatal screening for familial hypercholesterolaemia, in: Social Science \& Medicine 48, S. 1857-60.

Shell, Ellen Ruppel (2002): The Hungry Gene. The Science of Fat and the Future of Thin. New York: Atlantic Monthly Press.

Simpson, Joe L./ Ljungqvist, A./ Ferguson-Smifh, M. A./ de la Chapelle, A./ Elsas, L. J./ Ehrhardt, A. A./ Genel, M./ Ferris, E. A./ Carlson, A. (2000): Gender Verification in the Olympics., in: Jama - Journal of the American Medical Association 284(12), S. 1568-1569.

Somek, Alexander (2003): Genetic Discrimination, in: Society 40 (6), S. 35-43.

Sport 1 (2002): Fromme: »Männer müssen ihre Männlichkeit nicht beweisen«, in: www.sport1.de/coremedia/generator/www.sport1.de/Sportarten/Mehr/Volleyball (4. September 2002)

Stockter, Ulrich (2004). Der unberechenbare Mensch, in: Gen-Ethischer Informationsdienst, Nr. 167, S. $38-42$.

Traufetter, Gerald (2003): Geisel der eigenen Gene, in: Der Spiegel, Nr. 42, S. 216-218.

Van den Boer-van den Berg, Hanneke M. A./ Maat-Kievit, Anneke A.(2001): The whole truth and nothing but the truth, but what is the truth? in: Journal of Medical Genetics 38, S. 39-42.

Van Dijck, José (1998): Imagenation. Popular Images of Genetics. New York: New York University Press.

Volz, Sibylle 2003: Diskriminierung von Menschen mit Behinderung im Kontext von Präimplantationsund Pränataldiagnostik, in: Sigrid Graumann/ Kathrin Grüber (Hg.), Medizin, Ethik und Behinderung. Frankfurt am Main: Mabuse Verlag, S. 72-88.

Wailoo, Keith (2001): Dying in the City of the Blues. Sickle Cell Anemia and the Politics of Race and Health. Chapel Hill und London: The University of Northern Carolina.

Waldschmidt, Anne (1996): Das Subjekt in der Humangenetik. Expertendiskurse zu Programmatik und Konzeption der genetischen Beratung 1945-1990. Münster: Verlag Westfälisches Dampfboot.

Wasserman, David/ Wachbroit, Robert(2001): Genetics and Criminal Behavior. Cambridge: Cambridge University Press.

Weingart, Peter (1992): Politik und Vererbung: Von der Eugenik zur modernen Humangenetik. in: Eckart Voland (Hg.), Fortpflanzung: Natur und Kultur im Wechselspiel. Versuch eines Dialogs zwischen Biologen und Sozialwissenschaftlern. Frankfurt am Main: Suhrkamp, S. 28-50. 
Weingart, Peter/ Kroll, Jürgen/ Bayertz, Kurt (1992): Rasse, Blut und Gene. Geschichte der Eugenik und Rassenhygiene in Deutschland. Frankfurt am Main: Suhrkamp.

Weß, Ludger (1992): Eugenik im Zeitalter der Gentechnologie - Vom Zwang zur freiwilligen Inanspruchnahme. in: Anne-Dore Stein (Hg.), Lebensqualität statt Qualitätskontrolle menschlichen Lebens. Berlin: Marhold, S. 65-82.

Wolbring, Gregor (2001): Folgen der Anwendung genetischer Diagnostik für behinderte Menschen. Berlin: Gutachten erstellt im Auftrag der Enquete-Kommission des Deutschen Bundestages »Recht und Ethik der modernen Medizin«.

Wolf, Ulrich (1997): Identical mutations and phenotypic variation, in: Human Genetics 100, :305-321.

Wolf, Susan M. (1995): Beyond >genetic discrimination $<$ Toward the broader harm of geneticism, in: Journal of Law Medicine \& Ethics 23, S. 345-353.

Yahoo Financial News (2004): myDNA Media Endorses Passage of the Genetic Non-Discrimination Act of 2003, in: Yahoo Financial News, 21. Juni 2004.

Yoxen, Edward J. (1984): Constructing Genetic Diseases, in: Troy Duster/ Karen Garrett (Hg.), Cultural Perspectives on Biological Knowledge. Norwood/ NJ: Ablex Publishing Corporation, S. 41-62.

Zimmern, Ron L. (1999): Genetic Testing: a Conceptual Exploration, in: Journal of Medical Ethics 25, S. 151-156. 